\title{
OPTIMAL ROUTE DETERMINATION TO PROVIDE RELIEF FOLLOWING AN EARTHQUAKE USING THE TRAFFIC DENSITY RATIO (CASE STUDY: ISFAHANS FIRE STATIONS)
}

\author{
Seyed Ahmad Almasi ${ }^{1}$, Mohammad Mehdi Khabiri ${ }^{1{ }^{* *}}$, Mehdi Fallah Tafti ${ }^{1}$, Meisam Akbarzadeh ${ }^{2}$ \\ ${ }^{1}$ Department of Civil Engineering, Faculty of Engineering, Yazd University, Yazd, Iran \\ ${ }^{2}$ Department of Transportation Engineering, Isfahan University of Technology, Isfahan, Iran \\ *E-mail of corresponding author: mkhabiri@yazd.ac.ir
}

\section{Resume}

Despite the very important role of primary arteries and transportation network in providing relief for regions affected by an earthquake and black spots, they have received less attention. Therefore, in the current study, at first, the status quo of the traffic black spots and safe regions was identified to predict the movement direction, evacuation of residents from their habitat and temporary residence using the region zoning. The trips were assigned to the network based on the trip distribution matrix and their relevant travel times both related to the crisis state. The results indicated that out of 94 traffic regions, located in the area under investigation, 7 regions were put in the very low risk or safe regions group and 10 traffic regions were put in a very high-risk group. Additionally, the results indicated that out of 794 links, located in the area under investigation, about 32 links will have a very undesirable status following an earthquake.

Available online: https://doi.org/10.26552/com.C.2021.1.F20-F32

\section{Article info}

Received 1 May 2020

Accepted 2 July 2020

Online 12 November 2020

\section{Keywords:}

earthquake, crisis management, emergency evacuation, optimal route selection, fire stations

\section{Introduction}

The occurrence of severe earthquakes, especially in large cities, can lead to widespread human loss. The transportation network is essential for saving lives of injured and providing them with quick medical care. In order to reduce the possible human damages in an earthquake in any city or region, it would be necessary to assess the performance of the transportation network in response to demands to provide relief to travels following an earthquake. One of the issues, which most cities in the world are facing, is natural disasters [1]. These disasters have already killed three million people during the last 25 years and have imposed $\$ 23$ billion costs in financial damages. Meanwhile, earthquake is one of the most common disasters worldwide and in 2001 was reported as the deadliest event in the world. In Iran, from 1955 to 1995, more than 150,000 people have lost their lives due to earthquakes. The majority of new technologies allow the user to select the best route depending on numerous factors, including road length, grade and speed [2]. Today, as the density of big cities grows and the city's outskirts expand, a dangerous situation occurs in the event of a crisis. The main part of the reaction operation in an earthquake event is relief effort and its main purpose is to reduce casualties during the first hours after the earthquake. In previous earthquakes, the importance of speeding and reducing the time required for relief vehicles to pass through the traffic following an earthquake is highlighted. Goretti et al. [3] took note of the importance of the post-earthquake safety assessments by the European Union Civil Protection Team (EUCPT) after the Ecuadorian 7.8Mw earthquake on April 16, 2016. Helderop and Grubesic [4] explored the implications of network disturbance in their study to provide vulnerability analysis and emergency response in the event of an exacerbation of an alternative network that maintains important information in the network. Extensive research with simulation software has been used to model drivers' traffic behavior, for example, in assessing the capacity of urban roads according to the Slovak standard of simulations in PTV VISSIM and other software, [5].

Various views have been expressed on the vulnerability of the road network and the disruption of traffic after the crisis [6]. In order to find the best possible network, optimal methods for comparing failure scenarios have been used [7]. Result of identifying the critical situations is the approach used to evaluate the different possibilities of degradation of a network in an event [6]. The critical positions of a traffic area in a network are said to be the most effective on the network access flow [8]. In the present study, a vulnerability zoning map related to the transport network risk is obtained and with it, the network reliability, the traffic volume, the risk of each link and its serviceability are calculated. Bell et al. [9] conducted 
extensive research on network reliability. In addition, Gunnec and Salman [10] conducted a network reliability review study and defined reliability as the ability of the network to continue service in degradation conditions. Reliability of the travel time was first introduced to account for the reduction in capacity resulting from the road failures and as a function of the travel times ratio is expressed in abnormal (faulty) and normal modes [10]. When this ratio is close to one, the link operates in an ideal capacity and if it approaches infinity, the destination is not accessible due to the severity of congestion on some links. The sudden demand on the network, with the aim of uncertain travel, especially in times of crisis, is also a matter in considering the travel time reliability, but less attention has been paid to it [11]. Generally, the travel-time reliability criterion is useful for evaluation of the network performance based on the quality of service that should be maintained in daily traffic performance. In 2004, Yao et al. [12] studied the vital arteries functions in earthquake conditions and interaction of the vital arteries Poorzahedy and Shetab Bushehri calculated reliability of a small network and provided a criterion for the importance of links, based on the surplus of the user's interest in the simple deterministic route selection models or the non-deterministic (random) balance of the user [13-14]. Khademi et al. studied a postearthquake response and determined the optimum route for cars in the network [15].

Lu et al. (2016) planned to rebuild the urban road network caused by rain, snow and other adverse weather conditions, traffic accidents and the daily urban network conditions. They used greedy algorithm to retrieve the network after the crisis. The results have shown that this method is the most effective solution for identifying the critical links on the network [16].

The above review indicates that in previous studies, only one of the following two methods has been used for computation of the network reliability, i.e. either the hazard zonation maps have been used or the traffic flow on the road network has been analyzed. However, it seems to be more appropriate to use a combination of both methods and therefore, this innovative approach was adopted in this study. Thus, both network zoning maps and the traffic flow on the road network, obtained from a trip assignment processes, based on the links travel times in crisis situations, have been adopted in this study. As a case study, the performance of the street network of the city of Isfahan has been investigated against a hypothetical earthquake. This street network comprises all the major and minor arterial streets and a number of local access streets in general, the network conditions were considered as close as possible to reality to produce reliable results.

In this study, serviceability is defined as a combination of the street network vulnerability and the zoning map, using criteria such as the height of the buildings - the life period of the buildings, which is a number between zero and one for each rig. In the serviceability index or SC, the higher the vulnerability of the surrounding buildings, i.e. closer to one, the lower the serviceability of their surrounding streets. If the serviceability of the streets were close to zero, it means that the buildings around are not in the good condition and would fall due to an earthquake and due to street blockage the traffic flow on the street would be reduced to zero. This coefficient is calculated by:

serviceability $=1$ - vulnerability.

Due to the fact that an earthquake of magnitude 5 Richter does not destroy the buildings of medium risk, low risk and very low risk, the vulnerability is calculated as:

$$
\begin{aligned}
\text { the number of cells with very } \\
\text { vulnerability }=\frac{\text { vulnerability around the crossing }}{\text { total of the surrounding cells }} .
\end{aligned}
$$

In order to calculate the serviceability of links, located along the paths between the origin-destination pairs, the post-crisis network simulation methods were used in the following steps.

The transportation network of Isfahan was modeled in TransCad software using 2015 census information.

Using a questionnaire based survey, the amount of travel demand after the earthquake and the impact of the local discharges on the traffic network, the magnitude of traffic crisis was calculated.

Traffic flows on the network links were estimated using the trip production and attraction data values obtained for 15 areas of Isfahan using the TransCad software.

Based on the location of the network links on the city's vulnerability map, the serviceability index for each link was determined.

Using the effect of serviceability on the travel time, the critical travel time was calculated for each network link.

Using the critical travel time for each link, the optimal routes for relief vehicles to reach the high-risk areas, which were identified by the TransCad software.

Based on the results, the network traffic shortcomings under current conditions were evaluated and discussed.

Regarding the innovation of this study, it can be said that so far no similar study has been carried out for Isfahan and no TransCad software has been used in previous studies.

\section{Research method}

\subsection{An overview of the city of Isfahan}

Isfahan Province with a total area of 107045 square kilometers, accounts for $6.25 \%$ of the total area of Iran. This province is located between 30 to 34 degrees and 30 minutes' north latitude and 49 degrees and 36 minutes to 55 degrees and 32 minutes' east longitude in the center of Iran. According to the 2015 census, the population of the city of Isfahan has reached around 2 million. The central district of Isfahan has the highest population density in comparison to the other districts in the city. Most of the traffic passes through the central district that represents the old city 
and majority of historic sites are located in this district. Moreover, about $70 \%$ of the city's relief centers are located in this area. Therefore, the purpose of this area selection was to reduce human casualties due to the high population density and risk assessment of urban roads. The research method is a combination of documentary, descriptive and analytical research methods. The study area is main streets (major distributors, minor collectors and local access streets) in the central area of Isfahan City. This information is obtained through detailed results of the general population and housing census, a 1.2000 map of Isfahan, detailed plans of the city of Isfahan as well as through documents and journals and related books. The results of this study have been obtained through the ArcGIS, Transcad, Excel software, as well as AHP and Expert Choice software for weight measurement and determination of vulnerability and efficiency of roads and vital transport routes. According to the vulnerability coefficient of each link in the ArcGIS software and importing into the TransCad software, the serviceability of each link for the central area of Isfahan, has finally been identified as the optimal route for any relief vehicle to reach the accident areas. Using the ArcGIS software, land use maps, building density, population density, building life, distance from fault, type of building, number of construction floors and degree of enclosure were modeled. The vulnerability map is then generated in three steps. At the first stage, the main maps that are effective in the destruction of the earthquake are ranked and scored in importance and are also ranked according to the criteria for each major criterion. In the second stage, these criteria are gathered in the ArcGis software using the Raster Composite Computation Function. In the third step, according to the scores of each map, the maps are merged with the ArcGis software using the weighted sum of orders. In the following, the map is divided into 5 codes from the very low risk to high risk. Since in the magnitude 5 earthquake, the highrisk buildings have a high probability of falling, by division of the area of building code 5 into the total area of the surrounding buildings, the coefficient of vulnerability of each link is calculated as a link failure probability.

After zoning the studied area, vulnerable buildings were identified in each section and the probability of blockage of each link was calculated. The links that were able to handle high traffic (serviceability less than 25\%) were removed from the network links. After reviewing the opinion of the experts, since the travel time increases with reduction of serviceability, it tends to infinity and with the close availability of service, there is no change in the number of free travel time. Therefore, in general, one can consider three hypotheses for free service life and free travel time as follows: a) inverse relation of degree 2, b) logarithmic relationship, c) linear inverse relationship.

\subsection{Principles and method of research}

Assuming the inverse relationship between the free travel time and the probability of the link obstruction, probability of the link obstruction was applied as a coefficient in the travel time function to calculate the critical travel time. After allocating traffic, each bow is affected by the traffic from the adjacent links obstruction, based on the same link obstruction probability [17]. After loading the network, the optimal route has been obtained for any desired source-destination:

$C_{0}=\sum_{i=1}^{n} t_{i} * x_{i}$

In this case $t_{i}$ is the travel time of each link in normal mode and $x_{i}$ is the flow rate per link in normal mode and $\mathrm{C}_{0}$ are the link costs in the normal mode. Therefore, the greater the flow of traffic or the travel time, the greater the costs of travel on the link:

$C_{0}^{e}=\sum_{i=1}^{n-1} t_{i}^{e} * x_{i}^{e}$

In this case, $t_{i}^{e}$ is the travel time of the link in the event that one of the network links is interrupted and $x_{i}^{e}$ xi e is the traffic flow on the link in the event that one of the network links is cut off and $C_{0}^{e}$ are the costs of the link travel in the event that one of the network links is deleted.

Due to the linkage obstruction, the travel time of all links increases. As a result, the friction of the traffic of each link increases [17]. On the other hand, travel time links depends on link service capabilities. Therefore, the lower the link functionality is, the higher travel time or travel costs are:

$t_{\text {critical }}=\frac{t_{0}}{s c}$

where $s c$ is a service function and shows that the less service the link is, the higher its free travel time. In fact, in links with the serviceability close to zero, the travel time has increased significantly and when allocating traffic that link was removed from the competition and the traffic was not allocated, i.e. the link was actually blocked. In the links for which the serviceability is close to 1 , the buildings around the streets have no effect on changing the link conditions and the traffic allocation in those links are behaving like normal.

In order to calculate the link failure, the information was obtained from the seismic zonation of the city of Isfahan. In these calculations, assumptions were made to simplify and rationalize the process of calculations, which are as follows:

- Only the failure of the buildings located adjacent to the street links would affect the damage caused by the link tissue.

- Another failure of the link is the inability to withstand the link traffic load due to adjacent arcing obstruction.

- The probability of destruction of buildings in each area for all the links is equal to the percentage of buildings damaged in links.

- It was assumed that the network was affected by a magnitude 5 earthquake and its focal point was in the center of Isfahan, with major disruptions in the regions 
Table 1 Weighting results of one of the AHP selective criteria

\begin{tabular}{|c|c|c|}
\hline criteria & building type & weight factor \\
\hline \multirow{5}{*}{ building quality } & concrete-steel & 0.49 \\
\hline & metal-brick & 0.13 \\
\hline & brick- adobe & 0.22 \\
\hline & wooden- adobe & 0.25 \\
\hline & adobe & 0.32 \\
\hline \multirow{4}{*}{ building age } & $0-10$ & 0.10 \\
\hline & $10-20$ & 0.16 \\
\hline & $20-30$ & 0.31 \\
\hline & $>30$ & 0.42 \\
\hline \multirow{7}{*}{ population density } & $<50$ & 0.02 \\
\hline & $50-100$ & 0.06 \\
\hline & $100-150$ & 0.09 \\
\hline & $150-200$ & 0.13 \\
\hline & $200-250$ & 0.16 \\
\hline & $250-300$ & 0.24 \\
\hline & $>300$ & 0.29 \\
\hline \multirow{6}{*}{ building density } & $15-50$ & 0.06 \\
\hline & $50-75$ & 0.08 \\
\hline & $75-100$ & 0.13 \\
\hline & $100-150$ & 0.138 \\
\hline & $150-250$ & 0.24 \\
\hline & $250-300$ & 0.31 \\
\hline \multirow{5}{*}{ land use } & very low risk & 0.04 \\
\hline & low risk & 0.10 \\
\hline & medium risk & 0.16 \\
\hline & high risk & 0.29 \\
\hline & very high risk & 0.41 \\
\hline \multirow{6}{*}{ distance from fault (m) } & $<1000$ & 0.06 \\
\hline & $1000-2000$ & 0.08 \\
\hline & $2000-4000$ & 0.13 \\
\hline & $4000-6000$ & 0.138 \\
\hline & $6000-8000$ & 0.24 \\
\hline & $8000-10000$ & 0.31 \\
\hline
\end{tabular}

1 and 3 and part of other areas and percentage of the damaged buildings that caused the link obstruction were considered with this assumption. Therefore, buildings outside the study area are not affected by this earthquake.

\section{Data and analysis}

In order to investigate the role of communication networks and vulnerability of the building components in traffic areas, it is necessary to examine factors such as population and construction densities, land use, quality of buildings, etc. Thus, the effective index of vulnerability of the building components in the traffic areas of the central area of the city of Isfahan against an earthquake, including the quality of buildings, population density, construction density, land use risk, distance from fault, building life, as well as vulnerabilities in network paths including degree of confidentiality, building quality, building life, fault separation by traffic areas and network links, were investigated. In each study, the selected criteria should be proportional to the purpose of the study and be selected with the opinion of the experts. In this study, the main goal is to relieve and reduce casualties after earthquakes. Therefore, the criteria such as construction density and population density are of a great importance, as well as distance from faults and building life. Moreover, the type of building is the most 


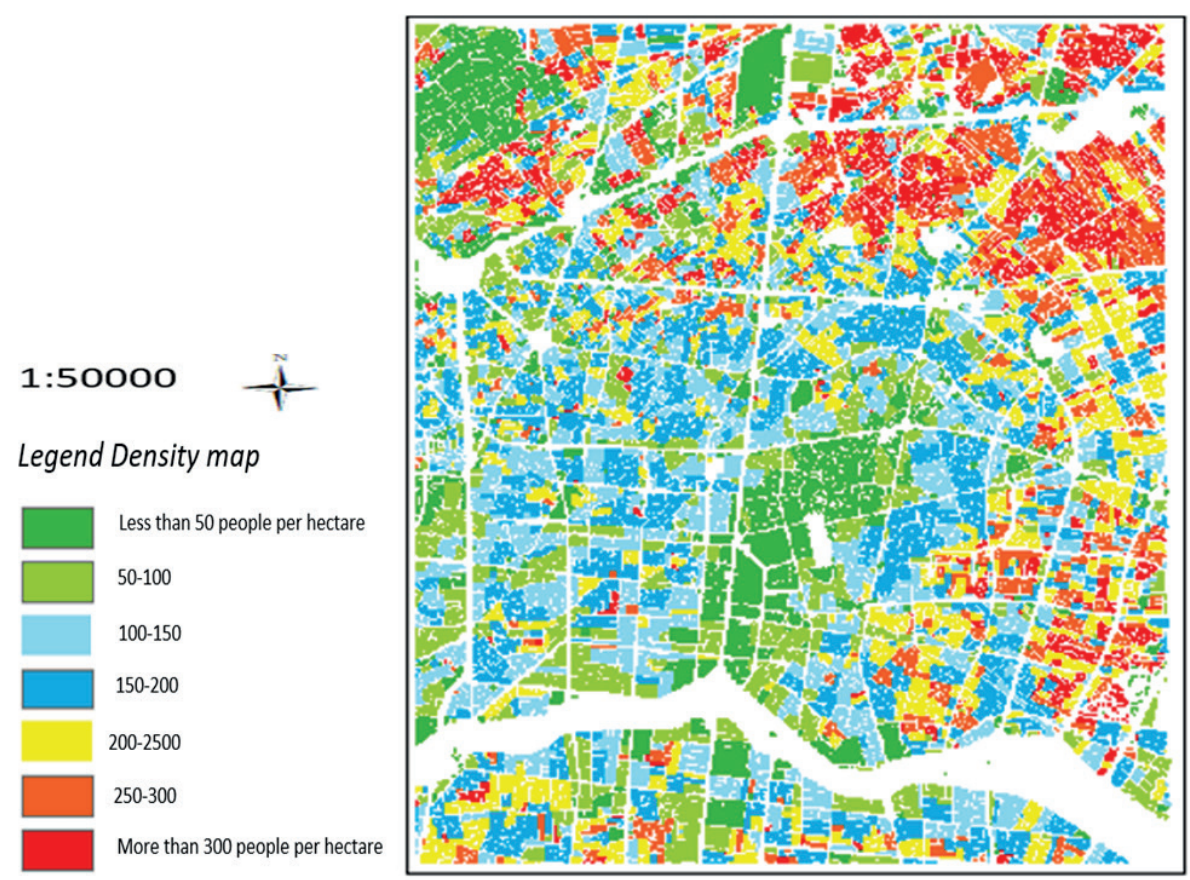

Figure 1 Density GIS map indicators for the risk assessment

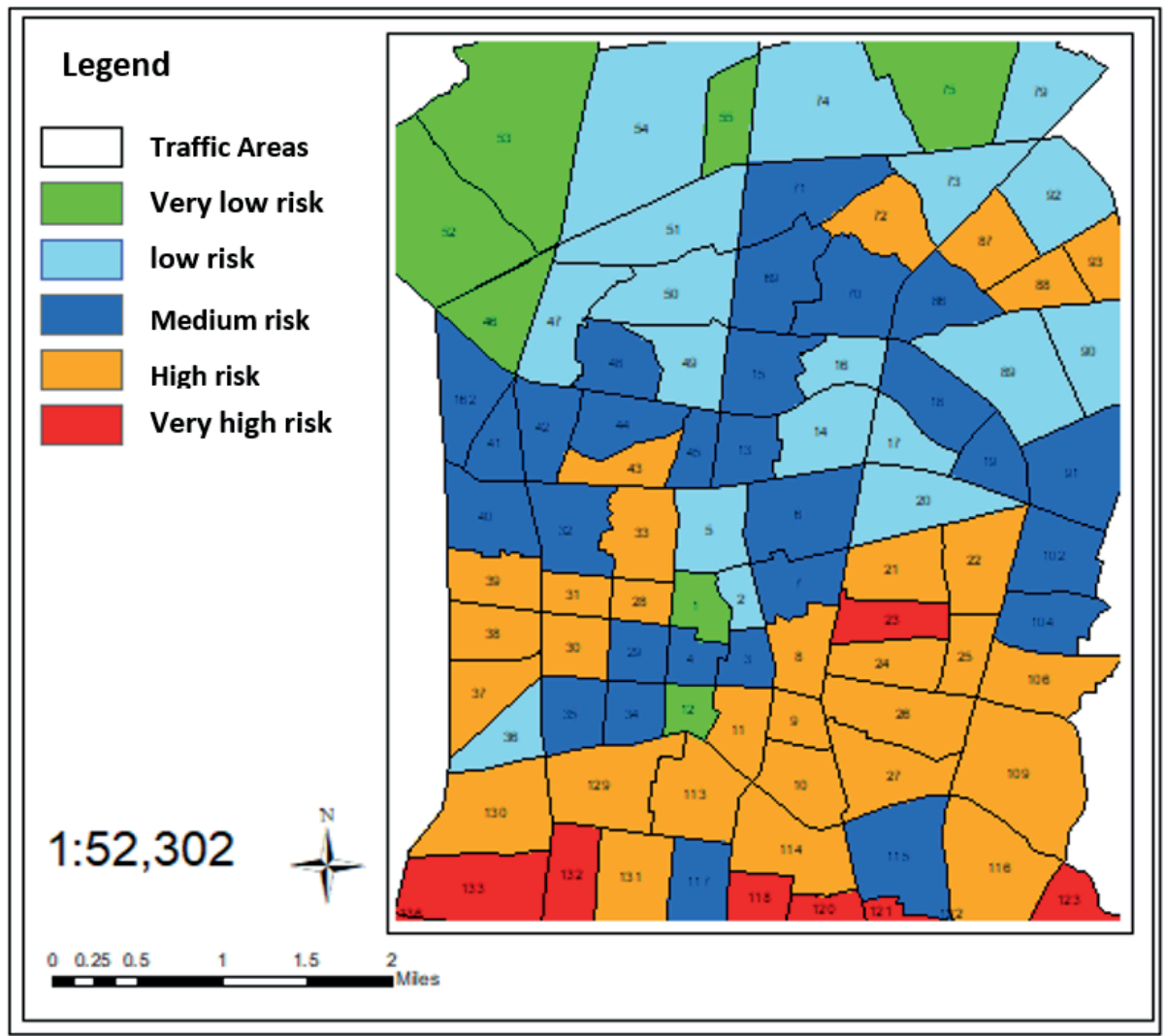

Figure 2 Zoned map of the study area divided by the traffic areas

important criterion for vulnerability studies, which is also shown in Table 1 [17-18]. On the other hand, the criterion of degree of confinement (elevation to the width of the passageway) and land use is a good indicator for identifying high-risk passages, which has been used in most studies in the field of this indicator. Figures 1-4 show the steps that were described.
The criteria for weighting factors are based on a combination of Resource Criteria 15, 16 and 17. The method considered in this paper for weighing risk factors is the analytic hierarchy process (AHP) method. That is a structured technique for organizing and analyzing complex decisions, based on mathematics and psychology. It was developed by Taylor, M. I. Page 6 - t represents an 


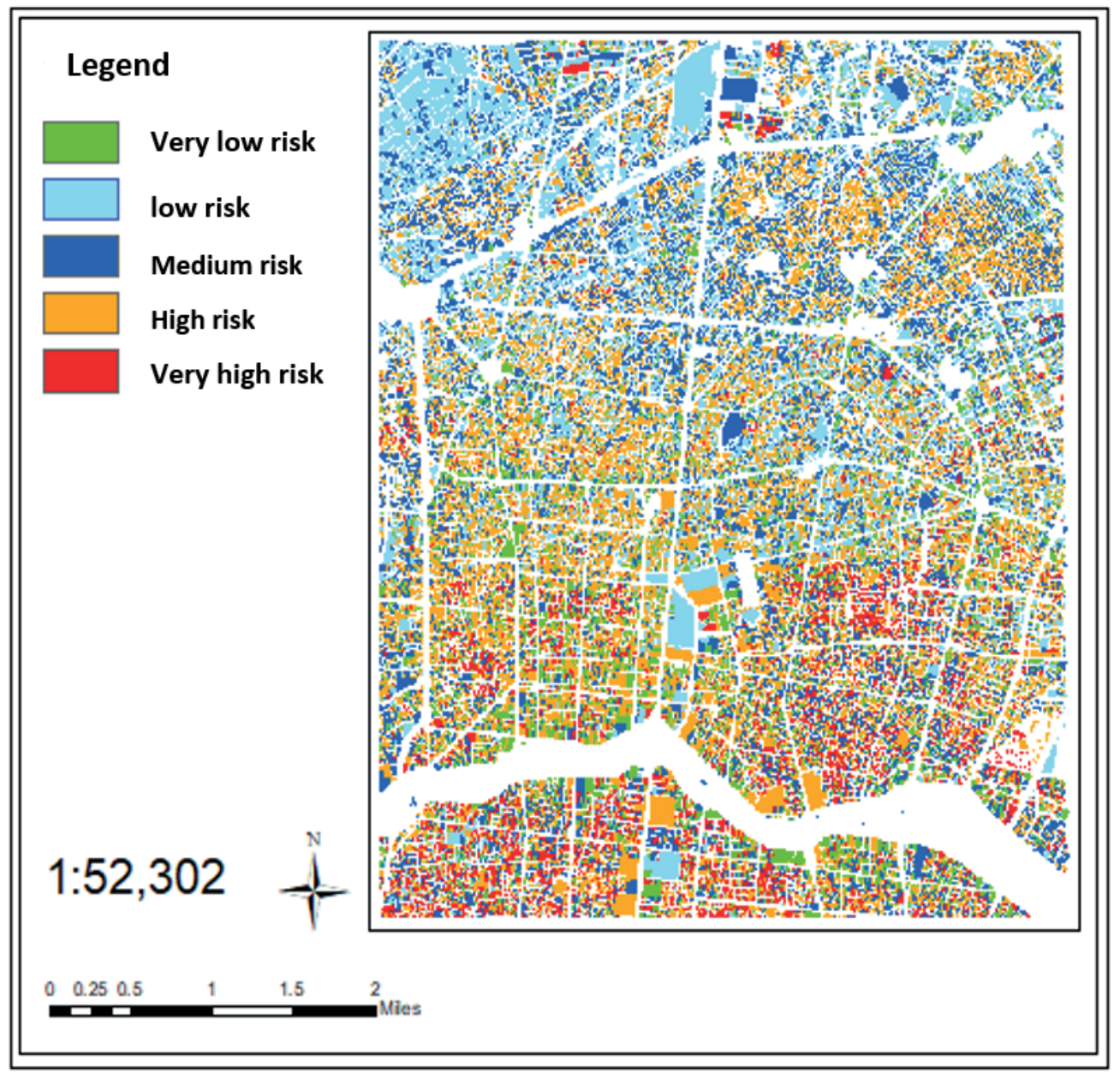

Figure 3 Earthquake vulnerability zoning map of the investigation area

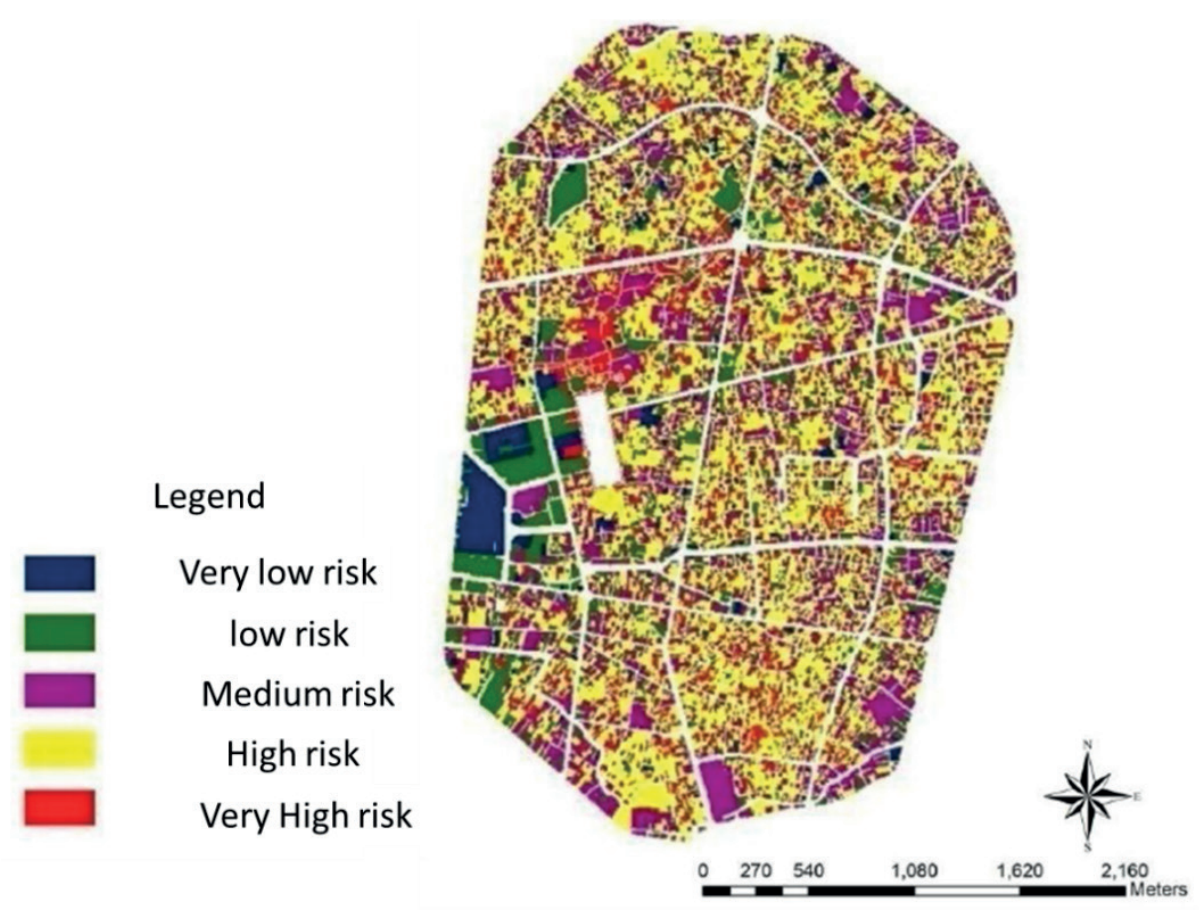

Figure 4 Sample GIS map indicators for the risk assessment [18] 
Table 2 An example of the vulnerability situation of secure traffic areas for temporary and post-discharge risk per unit pixel $(1 m * 1 m)$

\begin{tabular}{|c|c|c|c|c|c|c|c|}
\hline row & $\begin{array}{c}\text { traffic area } \\
\text { number }\end{array}$ & very low risk & low risk & medium risk & risky & very risky & sum \\
\hline \multicolumn{8}{|c|}{ vulnerability status of secure traffic areas for temporary accommodation } \\
\hline \multirow{2}{*}{1} & 1 & 13093 & 133004 & 8967 & 46927 & 30 & 202021 \\
\hline & Area $(\%)$ & 6.48 & 65.84 & 4.44 & 23.23 & 0.01 & 100 \\
\hline \multirow{2}{*}{2} & 12 & 26201 & 19835 & 18535 & 20078 & 6478 & 91127 \\
\hline & Area $(\%)$ & 28.75 & 21.77 & 20.34 & 22.03 & 7.11 & 100 \\
\hline \multirow{2}{*}{3} & 46 & 18776 & 150103 & 77604 & 68951 & 2092 & 317526 \\
\hline & Area (\%) & 5.91 & 47.27 & 24.44 & 21.72 & 0.66 & 100 \\
\hline \multicolumn{8}{|c|}{ vulnerability status of hazardous traffic areas } \\
\hline \multirow{2}{*}{4} & 23 & 23085 & 7749 & 65142 & 87752 & 75011 & 258739 \\
\hline & Area (\%) & 8.92 & 2.99 & 25.18 & 33.92 & 28.99 & 100 \\
\hline \multirow{3}{*}{5} & 118 & 10044 & 25294 & 20216 & 61621 & 126749 & 243924 \\
\hline & Area (\%) & 4.12 & 10.37 & 8.29 & 25.26 & 51.96 & 100 \\
\hline & 119 & 46911 & 14124 & 47705 & 55778 & 109626 & 274144 \\
\hline 6 & Area (\%) & 17.11 & 5.15 & 17.40 & 20.35 & 39.99 & 100 \\
\hline
\end{tabular}

Table 3 An example of the serviceability of links with high vulnerability (relation 2) after an earthquake

\begin{tabular}{ccccccccc}
\hline link code & $\begin{array}{c}\text { very low } \\
\text { risk }\end{array}$ & $\begin{array}{c}\text { low } \\
\text { risk }\end{array}$ & $\begin{array}{c}\text { medium } \\
\text { risk }\end{array}$ & risky & $\begin{array}{c}\text { very } \\
\text { risky }\end{array}$ & sum & $\begin{array}{c}\text { link failure } \\
\text { probability } \\
\text { (percent) }\end{array}$ & $\begin{array}{c}\text { serviceability } \\
\text { (percent) }\end{array}$ \\
\hline 6823039 & 0 & 0 & 0 & 141 & 2420 & 2561 & 94.49 & 5.51 \\
10411042 & 0 & 0 & 0 & 2 & 30 & 32 & 93.75 & 6.25 \\
10426994 & 0 & 0 & 0 & 18 & 1658 & 1676 & 98.93 & 1.07 \\
10591061 & 2336 & 1129 & 9 & 1188 & 20295 & 24957 & 81.32 & 18.68 \\
11126266 & 0 & 4 & 0 & 0 & 6623 & 6627 & 99.94 & 0.06 \\
12071208 & 4 & 2451 & 0 & 2 & 10110 & 12567 & 80.45 & 19.55 \\
12321233 & 0 & 0 & 0 & 1 & 114 & 115 & 99.13 & 0.87 \\
12621263 & 0 & 0 & 0 & 0 & 845 & 845 & 100.0 & 0.00 \\
12731266 & 0 & 7 & 0 & 8 & 2813 & 2828 & 99.47 & 0.53 \\
14561457 & 1615 & 0 & 0 & 143 & 7235 & 8993 & 80.45 & 19.55 \\
15151553 & 236 & 0 & 0 & 0 & 1248 & 1484 & 84.10 & 15.90 \\
15321545 & 719 & 1695 & 454 & 2708 & 32503 & 38079 & 85.36 & 14.64 \\
23387019 & 7 & 0 & 0 & 1 & 315 & 323 & 97.52 & 2.48 \\
\hline
\end{tabular}

accurate approach for quantifying the weights of decision criteria. Individual experts' experiences are utilized to estimate the relative magnitudes of factors through pairwise comparisons [19].

\section{Results and discussion}

Using the map analysis, it can be seen that the traffic areas 1-12 are based on criteria that are considered good, that is, the vulnerability in these areas is very low and areas
23-123 are very vulnerable. Table 2 shows the vulnerability of the safe areas and high-risk areas of traffic units in terms of pixel units.

Based on results of the proposed criteria, it is predicted that after the earthquake, the traffic area No 75 of the Isfahan Municipality is at risk of being in a very low risk and has higher safety than other traffic areas. The traffic area No 23 does not have a good status and after earthquakes, there would be a lot of damages. Regarding the role of the body of communication networks in the area, streets with sufficient width to provide better access to relief centers 
Table 4 Network link vulnerability status

\begin{tabular}{cc}
\hline number of links & vulnerability status \\
\hline 438 & very low risk \\
164 & low risk \\
111 & medium risk \\
48 & risky \\
33 & very risky \\
794 & sum \\
\hline
\end{tabular}

are in a better position in terms of vulnerability. In other words, these streets are ranked "too low" or "low" due to the division of the role of into 5 parts. In general, the existing trails in the north and center of the region are more vulnerable than the rest of the studied parts. Moving from south to north of the region increases the vulnerability (Table 3). This is due to the fact that the south of the region has a fairly large passageway and buildings of low ages.

According to the classification (Table 4), links with a vulnerability of less than $20 \%$ were very low vulnerable in the vulnerability category, links with between $20 \%$ and $40 \%$ in the low vulnerability category, links with a vulnerability of between $40 \%$ and $60 \%$ in the normal vulnerability, links whose vulnerability was between $60 \%$ and $80 \%$ in the high vulnerability group and links, whose vulnerability was higher than $80 \%$ were categorized in the very high vulnerable group.

The total number of links analyzed in the surveyed network was 794, since the number of these links and the segregation to the points are highly responsive and serviceable, so only links vulnerable to earthquakes in the high vulnerability category (vulnerability between 60 and 80 percent) and very high (vulnerability between $80 \%$ and $100 \%$ ), so as to identify these links, measures will be taken to manage the pre-crisis situation.

In the normal network mode, regardless of the effect of the link failure caused by the seismicity, Equation (4) was used to calculate travel time per link and to find the shortest travel time between a destination-destination pairs:

$$
T_{t}=t_{0}\left(1+\beta\left(\frac{v}{c}\right)^{\alpha}\right)
$$

where:

$T_{t}$ : link travel time in minutes,

$t_{0}$ : free travel time in minutes,

$v$ : Traffic volume at the link (in terms of vehicle equal to a car for 1 meter wide pass),

$c$ : link capacity.

In this case, the alpha value is equal to 4 and the beta value is equal to 0.15 .

In this study, to evaluate the impact of an earthquake on the link failure, the post-earthquake serviceability for each link is specified. In addition to the overwhelming effect of breaking down the network links, due to collapse of the surrounding buildings, links to a network that did not suffer from the critical traffic load and with reduced capacity were revealed, as well. For this reason, by assuming an inverse relationship between serviceability and free travel time, the critical travel time during the earthquake is calculated as:

$t_{\text {critical }}=\frac{t_{0}}{S C}$

where:

$t_{\text {critical }}:$ Critical free travel time in minutes,

$t_{0}$ : initial free travel time in minutes,

$s c$ : Serviceability between zero and one.

This relationship shows that the less service a link is, the higher its free travel time. In fact, for the links with serviceability close to zero, travel time have increased significantly. When allocating traffic, that link was eliminated from the competition and the traffic was not allocated, that is, the link is actually blocked. In links where their serviceability is close to 1 , that is, the buildings around the traffic jams have no effect on change of the link conditions and the traffic allocation in that link behaves like normal.

Since the impact of the traffic demand outside the scope of the study cannot be considered, it is assumed that the earthquake is strong - magnitude 5 and its focal area is investigated in the center of the range. Therefore, the impact of the buildings around the street outside the studied area is negligible and the serviceability for these links is considered 1 . Thus, the travel time in the crisis mode is calculated from:

$T_{\text {critical }}=t_{\text {critical }}\left(1+\beta\left(\frac{v}{c}\right)^{\alpha}\right)$.

In this case, the alpha value is 4 and the beta value is equal to 0.15

- The nodes of their priests end up in the traffic signal. The delay of the link is calculated from:

$d_{1}(v)=\frac{(c t-g)^{2}}{2 c t\left(1-\frac{v}{s}\right)}+32\left(\frac{v}{\left(\frac{g}{s}\right)}\right)^{2}+5$

where:

$d_{1}(v)$ : Average delay time for crossing the intersection in the desired street entrance to the intersection,

$v$ : The volume of the traffic flow at the intersection of the intended street entrance,

$s:$ discharge rate in saturation mode,

$g$ : The length of the green light in the direction of the desired street,

$C_{t}$ : The period of the light at the intersection. 
Table 5 Street transport quality index

\begin{tabular}{lcc}
\hline quality level & ratio $(\mathrm{V} / \mathrm{C})$ & index \\
\hline very favorable & $<0.35$ & $\mathrm{~A}$ \\
favorable & $0.35-0.5$ & $\mathrm{~B}$ \\
fairly favorable & $0.5-0.75$ & $\mathrm{C}$ \\
unfavorable & $0.75-0.9$ & $\mathrm{D}$ \\
very unfavorable & $0.9-1$ & $\mathrm{E}$ \\
obstruction and congestion & $>1$ & $\mathrm{~F}$ \\
\hline
\end{tabular}

Table 6 Number of fire stations in Isfahan city

\begin{tabular}{ccc}
\hline number of fire and rescue stations & median reach for the incident & number of fire lanterns \\
\hline 22 & 6 minutes and 20 seconds & 1375 \\
\hline
\end{tabular}

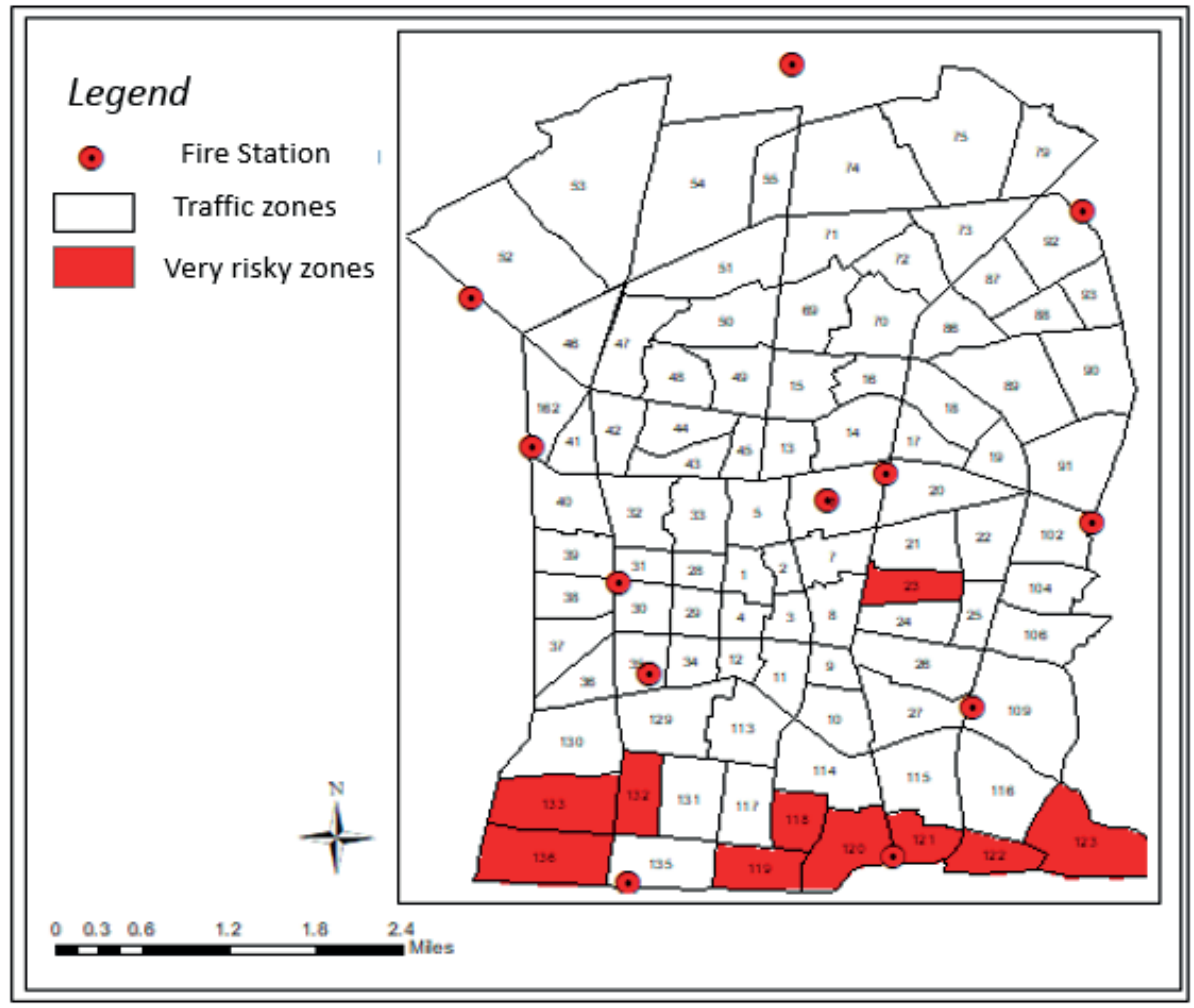

Figure 5 Location map of the fire stations and high risk areas in GIS

- The nodes, which their ancestors do not stop at the traffic signal, the link delay is calculated from:

$d_{2}(v)=d_{0}\left(2.5+2\left(\frac{v}{Q}\right)^{2}\right)$,

where:

$d_{2}(v)$ : Average delay time for crossing the intersection,

$Q$ : Practical capacity of intersecting streets,

$v$ : The volume of traffic flow in the desired street inlet to the intersection,

$d_{0}$ : Fixed coefficient of the delay time at an intersection without lights for streets entering the intersection. In the above relation, the value of $d_{0}$ is calculated as:

$d_{0}=a \times m$, where:

$m$ : number of permitted movements at the intersection (except bypassing)

$a$ : Delay coefficient.

In this part of the study, the traffic volume indicator and street capacity using the traffic model (V/C) (traffic to capacity ratio) have been used to determine the level of service and quality of traffic in the streets of Isfahan. The following describes the (V/C) coefficient and the quality of commuting.

Based on the standard classification (Table 5), the quality of the item is categorized into 6 classes based on different values. In this categorization, the quality of service at the service level A is in very favorable conditions and with increasing $(\mathrm{V} / \mathrm{C})$, this quality decreases to the service level $\mathrm{F}$. 


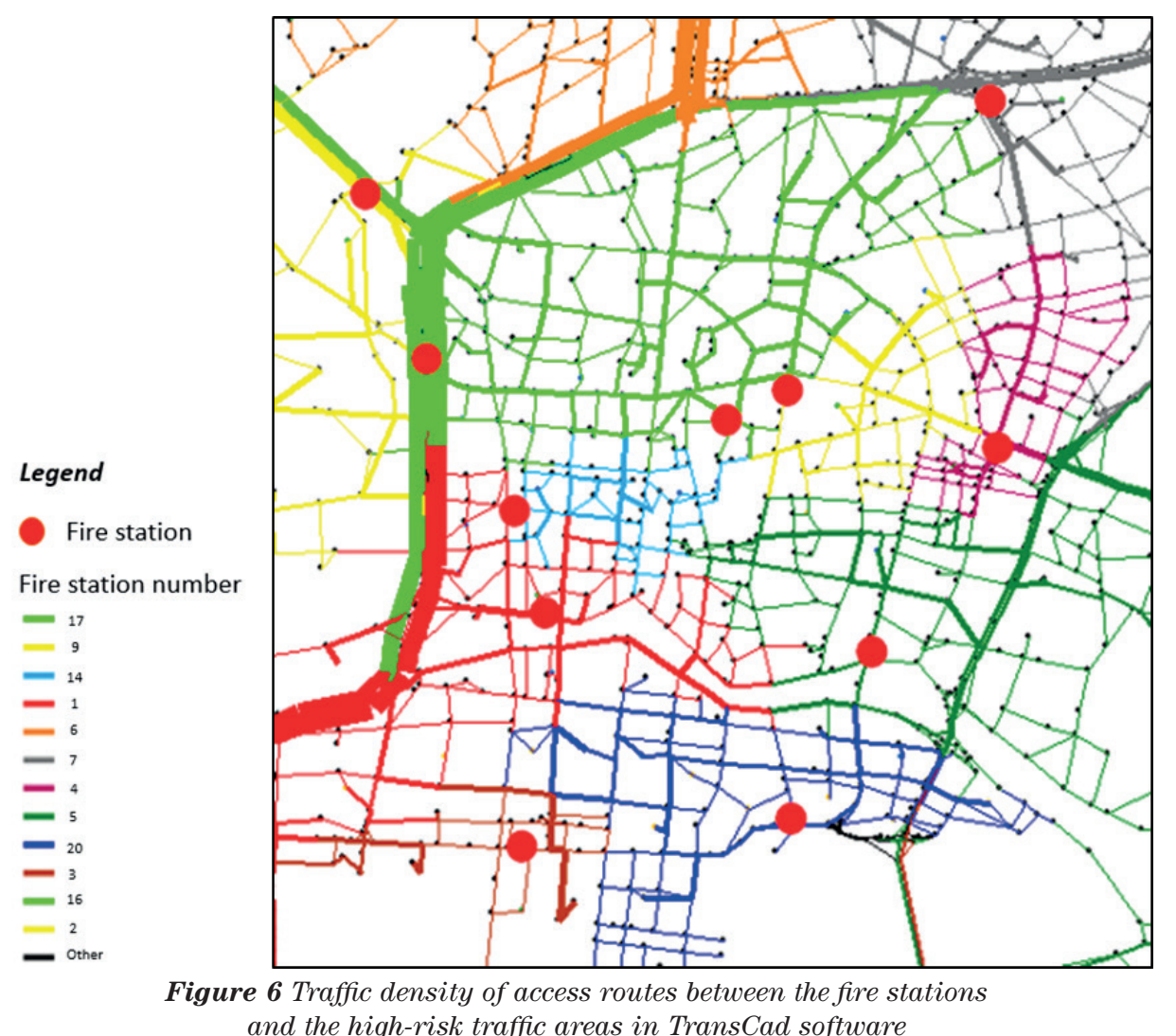

Table 7 Examples of links that have been blocked due to vulnerability

\begin{tabular}{|c|c|c|c|c|c|}
\hline link name & link code & $\begin{array}{l}\text { vulnerability rate } \\
\text { (percent) }\end{array}$ & $\begin{array}{l}\text { serviceability } \\
\text { (percent) }\end{array}$ & $\begin{array}{l}\text { initial free travel time } \\
\text { ( seconds) }\end{array}$ & $\begin{array}{l}\text { critical free travel } \\
\text { time (seconds) }\end{array}$ \\
\hline Kamal Ismail & 6823039 & 94.49 & 5.51 & 28 & 500 \\
\hline Taleghani & 10411042 & 93.75 & 6.25 & 10 & 150 \\
\hline Flower garden & 10426994 & 98.93 & 1.07 & 20 & 700 \\
\hline Flower garden 2 & 10591061 & 81.32 & 18.68 & 18 & 70 \\
\hline Kamal & 11126266 & 99.94 & 0.06 & 8 & 5850 \\
\hline Khayyam is heading south & 12071208 & 80.45 & 19.55 & 8 & 30 \\
\hline Khayyam moves north & 12321233 & 99.13 & 0.87 & 12 & 950 \\
\hline Sheikh Baha'i & 12621263 & 100.0 & 0.00 & 13 & 20000000 \\
\hline Saeb & 12731266 & 99.47 & 0.53 & 12 & 1952 \\
\hline Ibn Sina & 15321545 & 85.36 & 14.64 & 30 & 208 \\
\hline Dashtestan & 23387019 & 97.52 & 2.48 & 15 & 325 \\
\hline Bozorgmehr & 24012413 & 96.67 & 3.33 & 17 & 320 \\
\hline Bridge Bozorgmehr & 24272630 & 100.0 & 0.00 & 20 & 29000000 \\
\hline Mofateh & 24332432 & 82.80 & 17.2 & 28 & 152 \\
\hline
\end{tabular}

In order to investigate the relief organizations in the area under study, they were surveyed in a radius of 1000 meters outside the study area in Isfahan, as Table 6 . The city of Isfahan now has 22 stations, which should serve the entire city. According to the available statistics, the average reach for the incident is 6 minutes and 20 seconds. The city of Isfahan now has 1375 firefighters.

\subsection{Application of the proposed model}

After identifying the highly vulnerable areas and location of the fire stations to a radius of 1000 meters outside the scope of the study, it is necessary to determine the optimal route of these vehicles to reach the traffic areas (Figure 5). This path is determined by the final time travel 
Table 8 The shortest path from the fire stations to the traffic area of the incident during the earthquake

\begin{tabular}{|c|c|c|c|c|c|}
\hline fire station number & risky traffic area & $\begin{array}{l}\text { shortest path } \\
\text { (seconds) }\end{array}$ & fire station number & risky traffic area & $\begin{array}{l}\text { shortest path } \\
\text { (seconds) }\end{array}$ \\
\hline 5 & 23 & 560 & 20 & 118 & 95 \\
\hline 5 & 122 & 3150 & 20 & 119 & 210 \\
\hline 5 & 123 & 14250 & 20 & 121 & 621 \\
\hline 1 & 133 & 625 & 20 & 132 & 535 \\
\hline 1 & 138 & 1820 & 3 & 120 & 1812 \\
\hline
\end{tabular}

Table 9 Important fire stations in the investigation range in the earthquake scenario

\begin{tabular}{cccc}
\hline fire station number & $\begin{array}{c}\text { the number of risky traffic areas } \\
\text { covered }\end{array}$ & $\begin{array}{c}\text { the status of the traffic area } \\
\text { stage coverage radius (percent) }\end{array}$ & $\begin{array}{c}\text { th } \\
\text { in which the station is located }\end{array}$ \\
\hline 20 & 4 & 30 & very risky \\
5 & 3 & 20 & risky \\
1 & 2 & 10 & medium risk \\
3 & 1 & medium risk
\end{tabular}

function after allocation of the network in a critical state. In fact, according to the travel time, the shortest route is the optimal route.

As shown in Figure 6, the coverage radius of all the relief centers and fire stations is shown in the entire range. This coverage radius is partitioned based on the shortest travel time.

In this allocation, streets are divided into 5 categories according to the (V/C) ratio and are graphically plotted. Following the allocation of traffic, critical links were identified. Black links are the links, which have the capacity of crashing after the earthquake and disturb the network. Up to this point, links have been found to be critical and blocked due to the vulnerability of body parts, as well as links that have been identified due to the excessive traffic load of the network (both due to the people's behavioral crisis and the traffic load of the adjacent links blocked by the destruction of the body parts).

Based on the time of the final critical journey (after allocation), it has begun to reroute the relief vehicles. That is, at each stage, an accidental traffic area is considered as the destination and all the relay stations are selected as the source of the trip. After the implementation of the program, the closest area to the traffic area is specified based on the shortest travel time.

In Table 8 the travel time of all the link of the network, which is covered by the traffic area has been calculated and the shortest path between the two points has been identified. The priority is shorter, but if the emergency station does not have the capacity for relief, it will be reset from the nearest station.

According to information in Tables 6 and 7, Station 20, located in Traffic Area 109, has a very good position to access the high-risk areas and can provide assistance to $40 \%$ of the total risk areas, but it may suffer from a lack of capacity as it should be sent to 4 traffic areas simultaneously. On the other hand, placing this station in the traffic area 109, which is shown in Figure 5 as a high-risk traffic area, should be considered to prevent the station from being deactivated in the crisis state to reduce losses and provide quicker relief by appropriate measures, according to Table 9 .

Studies on the post-earthquake network serviceability so far have not addressed the exact vulnerability and traffic congestion separately, in fact, most of these investigations have addressed either tissue vulnerability or traffic congestion. Therefore, in this study, in addition to carefully examining the vulnerability of traffic areas and urban passages, providing a relationship of this capability has affected the free travel time.

\section{Conclusion}

In this research, the ArcGIS software first determined the role of the traffic areas of the studied area as well as the vulnerability of each traffic area. Then, by providing the role of the ability to serve each link was identified. After applying the service capability to free travel time, the critical travel time was obtained for each link. Finally, using the TransCad software and considering the location of the fire and air stations in the study area, the shortest route for the relief vehicles to reach each high-risk area of traffic was identified for earthquake scenario.

- The traffic area's physical quality is not enough to determine its vulnerability. Some other factors such as the construction and demolition densities, quality of the building and the building age are also very effective.

- The secure traffic areas are located in the north of the studied area, while the accidental traffic areas are situated in the south. After the earthquake, it is expected that a relatively large traffic wave would be created in the network for evacuation and temporary accommodation. This is the same result as the zoning of the Saidian study for District 3 of the municipality of Isfahan has been achieved and the accuracy of the study is acceptable.

- The high-risk traffic areas are located in close proximity, thus putting relief effortlessly. 
- $\quad$ The wider the width of the tunnel, the lower the degree of confinement and eventually the link vulnerability decreases.

Applying the results of this study could also help managers and decision makers to prioritize, refine and strengthen the urban transport network links, so they would be able to make the better decisions.

\section{Acknowledgement}

The present paper is extracted from a master dissertation at the Yazd University and funded by the Municipality of Isfahan, No. 121/96/2226.

\section{References}

[1] NTZEREMES, P., KIRYTOPOULOS, K. Evaluating the role of risk assessment for road tunnel fire safety: a comparative review within the EU. Journal of Traffic and Transportation Engineering [online]. 2019, 6(3), p. 282-296. ISSN 2095-7564. Available from: https://doi.org/10.1016/j.jtte.2018.10.008

[2] SIUHI, S., MWAKALONGE, J. Opportunities and challenges of smart mobile applications in transportation. Journal of Traffic and Transportation Engineering [online]. 2016, 3(6), p. 582-592. ISSN 2095-7564. Available from: https://doi.org/10.1016/j.jtte.2016.11.001

[3] GORETTI, A., HUTT, C. M., HEDELUND, L. Post-earthquake safety evaluation of buildings in Portoviejo, Manabi province, following the Mw7. 8 Ecuador earthquake of April 16, 2016. International Journal of Disaster Risk Reduction [online]. 2017, 24, p. 271-283. ISSN 2212-4209. Available from: https://doi.org/10.1016/j.ijdrr.2017.06.011

[4] HELDEROP, E., GRUBESIC, T. H. Streets, storm surge and the frailty of urban transport systems: a grid-based approach for identifying informal street network connections to facilitate mobility. Transportation Research Part D: Transport and Environment [online]. 2019, 77, p. 337-351. ISSN 1361-9209. Available from: https://doi.org/10.1016/j.trd.2018.12.024

[5] CELKO, J., KOVAC, M., HUSZAROVA, K. (2019). Influence of Selected Vehicle Maneuvers on Reduction of the Urban Roads Capacity. Communications-Scientific Letters of the University of Zilina [online]. 2019, 21(4), p. 81-89. ISSN 1335-4205, eISSN 2585-7878. Available from: http://komunikacie.uniza.sk/index.php/communications/article/ view/1522

[6] TAYLOR, M., SEKHAR, S., D'ESTE, G. Application of accessibility based methods for vulnerability analysis of strategic road networks. Network Spatial Economy [online]. 2006, 6, p. 267-291. ISSN 1566-113X, eISSN 1572-9427. Available from: https://doi.org/10.1007/s11067-006-9284-9

[7] SHEN, W., NIE, Y., ZHANG, H. Dynamic network simplex method for designing emergency evacuation plans. Transportation Research Record: Journal of the Transportation Research Board [online]. 2007, 2022(1), p. 1-25. ISSN 0361-1981, eISSN 2169-4052. Available from: https://doi.org/10.3141/2022-10

[8] HOLLY, M., SHULMAN, L. Estimating evaluation vulnerability of urban transportation systems using GIS. A thesis submitted to the Department of Geography in conformity with the requirements for the degree of Master of Arts. Ontario. Canada: Queen's University Kingston, 2008.

[9] BELL, M.G.H. AND Y. IIDA. Transportation Network Analysis. John Wiley \& Sons, New York. 1997.

[10] GUNNEC, D., SALMAN, F. S. Assessing the reliability and the expected performance of a network under disaster risk. Istanbul: College of Engineering, Koc University, 2006.

[11] RECKER, W., CHUNG, Y., CHEN, A., PARK, J., WANG, L., JI, Z., LIU, H., HORROCKS, M., OH, J.-S. Considering risktaking behavior in travel time reliability. California Partners for Advanced Transit and Highways (PATH). Research report. Berkeley: University of California, 2005.

[12] YAO, B, XIE, L, HUO, E. Study effect of lifeline interaction under seismic conditions. In: 13th World Conference on Earthquake Engineering: proceedings. 2004. 3152.

[13] POORZAHEDY, H., SHETAB BUSHEHRI, S. N. Network performance improvement under stochastic events with long term effects. Transportation [online]. 2005, 32(1), p. 65-85. ISSN 0049-4488, eISSN 1572-9435. Available from: https://doi.org/10.1007/s11116-004-1139-y

[14] CHEN, A., YANG, H., LO, H. K., TANG, W. H. Capacity reliability of a road network: an assessment methodology and numerical results. Transportation Research Part B: Methodological [online]. 2002, 36(3), p. 225-252. ISSN 0191-2615. Available from: https://doi.org/10.1016/S0191-2615(00)00048-5

[15] KHADEMI, N., BALAEI, B., SHAHRI, M., MIRZAEI, M., SARRAFI, B., ZAHABIUN, M., MOHAYMANY, A. S. Transportation network vulnerability analysis for the case of a catastrophic earthquake. International Journal of Disaster Risk Reduction [online]. 2015, 12, p. 234-254. ISSN 2212-4209. Available from: https://doi.org/10.1016/j.ijdrr.2015.01.009

[16] LU, G., XIONG, Y., DING, C., WANG, Y. An optimal schedule for urban road network repair based on the greedy algorithm. PLOS ONE [online]. 2016, 11(10), e0164780. eISSN 1932-6203. Available from: https://doi.org/10.1371/journal. pone. 0164780 
[17] ALMASI, S. A., KHABIRI, M. M., FALLAH TAFTI, M, AKBARZADEH, M. Development of a methodology to identify crucial emergency stations for quick relief response to the damaged urban areas following an earthquake (case study: Isfahan City Center). Health in Emergencies and Disasters Quarterly [online]. 2018, 3(3), p. 131-142. ISSN $2345-4210$. Available from: https://doi.org/10.29252/NRIP.HDQ.3.3.131

[18] SAIDIAN, Z. Evaluation and evaluation of critical transport arteries in the event of an earthquake: district 3 of Isfahan. Master's thesis. Yazd: Yazd University, 2014.

[19] TAYLOR, M.; SEKHAR, S. AND D ESTE, G. "Application of Accessibility Based Methods for Vulnerability Analysis of Strategic Road Networks”, Network Spatial Economy. (2006), 6: 267-291.

\begin{tabular}{ll} 
Notations & \\
\hline lists all the symbols & the meaning of the explanatory symbols \\
\hline $\mathrm{SC}$ & the serviceability index \\
$\mathrm{t}_{\mathrm{i}}$ & the travel time of each link in the normal mode \\
$x_{i}$ & the flow rate per link in the normal mode \\
$c_{0}$ & the link costs in the normal mode \\
$t_{i}{ }^{e}$ & the travel time of the link in the event that one of the network links is interrupted \\
$x_{i}{ }^{e}$ & the traffic flow on the link in the event that one of the network links is cut off \\
$C_{0}{ }^{e}$ & the costs of the link travel in the event that one of the network links is deleted \\
$T_{t}$ & the link travel time in minutes \\
$t_{0}$ & the free travel time in minutes \\
$v$ & traffic volume at the link (in terms of vehicle equal to car for 1 meter wide pass) \\
$\mathrm{C}$ & link capacity \\
$t_{t c r i t i c a l}$ & critical free travel time in minutes \\
$d_{2}(v)$ & average delay time for crossing the intersection \\
$Q$ & practical capacity of intersecting streets \\
$d_{0}$ & fixed coefficient of delay time at an intersection without lights \\
$d_{1}(v)$ & average delay time for crossing the intersection in the desired street entrance \\
$s$ & the discharge rate in the saturation mode \\
$g$ & the length of the green light in the direction of the desired street \\
$C_{t}$ & the period of the light at the intersection \\
\hline
\end{tabular}

